\title{
Screening for metabolic syndrome within a minority ethnic group (adult Gypsy people) in Hungary
}

\author{
Hidvegi $\mathrm{T}^{1}$, Hetyesi $\mathrm{K}^{2}$, Biro $\mathrm{L}^{3}$, Nadas $\mathrm{J}^{4}$, Jermendy $\mathrm{G}^{4}$ \\ 3rd Department of Medicine, Bajcsy-Zsilinszky Hospital, Budapest, Hungary. gyjermendy@mail.datanet.hu
}

\begin{abstract}
Background: Metabolic syndrome occurs more often among people living in poorer social conditions. The health status of the largest minority ethnic group in Hungary lags in many aspects behind that of the general population. Methods: To estimate the prevalence of metabolic syndrome a screening was initiated in the city of Györ among subjects aged 20-70 years who declared themselves as Gypsy. Subjects with known diabetes and cardiovascular disease were excluded. The diagnosis of metabolic syndrome was based on the ATP-III criteria.

Results: Among the 77 individuals screened (35 men, 42 women, age $46.9 \pm 10.6$ years, $x \pm$ SD) diabetes mellitus was found in 14 cases (18.2\%), and pre-diabetes (impaired fasting blood glucose (IFG) or impaired glucose tolerance (IGT) could be diagnosed in further 14 cases $(18.2 \%)$. Individual components of the metabolic syndrome occurred as follows: hypertension in 47 subjects $(61.0 \%)$, abnormal waist circumference in 40 individuals (51.9\%), abnormal HDL-cholesterol in 39 cases (50.6\%), abnormal triglycerides in 35 individuals $(45.5 \%)$ and abnormal fasting blood glucose in 15 subjects $(19.5 \%)$. Within the cohort metabolic syndrome could be diagnosed in 39 individuals (50.6 \%) without a significant gender difference (males 20/35 = 57.1\%; women: $19 / 42=45.2 \%, p>0.05)$.

Conclusion: The occurrence of metabolic syndrome and that of glucose intolerance is high among adult Gypsy people in Hungary. In order to recognise cardio-metabolic risks and to prevent their cardiovascular consequences, continuous health promotion and adequate medical care should be provided for the Gypsy population in Hungary (Tab. 5, Ref. 32). Full Text in PDF www.elis.sk.

Key words: Gypsy (gipsy) population, metabolic syndrome, glucose intolerance, screening, cardiovascular risk factors.
\end{abstract}

Based on linguistic and genetic data the Gypsy (Gipsy) people originated in Northern India and appeared in Europe at the time of the Byzantine Empire. Their habits, language, culture and religion separated them for a long time from the population of the host country and they suffered discrimination in several respects. The peak of this negative perception was the period of the Second World War. In the second half of the twentieth century assimilation efforts had been launched in response to social structural changes. Currently within Europe larger numbers of Gypsy people live in the Carpathian Basin, in Slovakia, Romania and Hungary (1).

In Hungary, the estimated number of Gypsy people is between 450,000 and 650,000 and their health indicators generally lag behind those of the general population. Presently, every eighth child born in Hungary is of Gypsy origin, but due to the higher infant mortality and the approximately 10-15 years shorter average life span, their proportion is lower among adults than among children (2). The change

${ }^{14}$ th Department of Medicine, Petz County Teaching Hospital, Györ, Hungary, ${ }^{2}$ Central Laboratory, Petz County Teaching Hospital, Györ, Hungary, ${ }^{3} \mathrm{Na}-$ tional Institute for Food and Nutrition Science, Budapest, Hungary, and ${ }^{4} 3 \mathrm{rd}$ Department of Medicine, Bajcsy-Zsilinszky Hospital, Budapest, Hungary

Address for correspondence: G. Jermendy, MD, PhD, DSc, 3rd Medical Department, Bajcsy-Zsilinszky Hospital, Maglódi út 89-91, 1106 Budapest, Hungary.

Phone/Fax: +36.1.4327533

Acknowledgements: The authors thank general practitioner colleagues Miklós Környei and Gabriella Cséka for their contribution in the screening. in lifestyle of the Gypsy population is an important topic of sociological research in Hungary. Health research previously focused on reporting upon more frequent occurrence of infectious diseases among the Gypsy people and only in recent years has the attention turned to the increasing importance of non-communicable diseases.

Knowledge related to the metabolic syndrome has considerably increased over the past few years. In spite of some uncertainty around the theoretical background, the practical use of the concept has not been questioned. This is true even if today instead of the metabolic syndrome the rather broader concept of cardiometabolic risk is used $(3,4)$.

In the literature a number of ethnic groups have been reported in whom a dramatic increase in obesity, metabolic syndrome, type 2 diabetes and other cardiovascular risk factors had been observed due to the shifting of the traditional way of life, involving regular physical activity, towards more sedentary lifestyle and unhealthy eating patterns $(5,6,7)$. At the same time it is also documented that returning to a traditional lifestyle from urban life in the reported ethnic group (Australian aborigines), resulted in a spectacular improvement in glucose and lipid parameters (8).

We hypothesized that metabolic syndrome and type 2 diabetes mellitus can often be expected in the Gypsy population in Hungary, as lifestyle and dietary characteristics of modern society affect also this ethnic group. We initiated a screening within the adult Gypsy population aiming to assess the occurrence of metabolic syndrome, type 2 diabetes and other cardiovascular risk factors. 


\section{Material and methods}

In the city of Györ and in the surrounding area general practitioners with practices with higher proportions of Gypsy families were asked to participate in the screening. Assistants to these general practitioners were engaged to find and inform the selected families about the aim of the screening. Attention was paid to involve health care workers of Gypsy origin in this work.

The screening involved subjects between 20-70 years of age and of both genders. We excluded subjects with known diabetes mellitus or cardiovascular disease. Finally 77 subjects agreed to participate in the study ( 35 men, 42 women; age: $46.9 \pm 10.6$ years), all of them declared themselves as Gypsy.

During the screening, basic anthropometric data (weight, height, body mass index (BMI), waist circumference, waist-hip ratio) were recorded, blood pressure was measured in a sitting position on the upper arm (using conventional mercury sphygmomanometers, we calculated the average of 4 measurements within 10 minutes in the resting state) and medical history data were also

Tab. 1. Diagnostic criteria of normal and abnormal glucose tolerance (WHO, 2006).

\begin{tabular}{|c|c|}
\hline State of glucose metabolism & $\begin{array}{l}\text { Glucose concentration, } \mathrm{mmol} / \mathrm{l} \\
\text { (venous plasma, laboratory } \\
\text { measurement) }\end{array}$ \\
\hline \multicolumn{2}{|l|}{ Normal glucose tolerance: } \\
\hline Fasting blood glucose & $\leq 6.0$ \\
\hline 2-hour value of OGTT & $<7.8$ \\
\hline \multicolumn{2}{|l|}{ Impaired fasting glucose (IFG) } \\
\hline Fasting blood glucose & $\geq 6.1$ but $<7.0$ (i.e. $6.1-6.9$ ) \\
\hline 2-hour value of OGTT & $<7.8$ \\
\hline \multicolumn{2}{|c|}{ Impaired glucose tolerance $(I G T)$ * } \\
\hline Fasting blood glucose & $\leq 7.0$ \\
\hline 2-hour value of OGTT & $\geq 7.8$ but $<11.1$ (i.e. $7.8-11.0$ ) \\
\hline \multicolumn{2}{|l|}{ Diabetes mellitus } \\
\hline Fasting blood glucose & $\geq 7.0$ \\
\hline 2-hour value of OGTT & $\geq 11.1$ \\
\hline
\end{tabular}

Tab. 2. The diagnosis of the metabolic syndrome according to the ATPIII diagnostic criteria (metabolic syndrome can be clinically diagnosed if out of the 5 criteria at least 3 (any 3 ) are present.

\begin{tabular}{ll}
\hline Abdominal type obesity & waist circumference \\
\hline Abnormal serum triglycerides & $>102 \mathrm{~cm}(\mathrm{men})$, or $>88 \mathrm{~cm}$ (women) \\
\hline Abnormal serum HDL-cholesterol & $<1.69 \mathrm{mmol} / \mathrm{l}(\geq 150 \mathrm{mg} / \mathrm{dl})$ \\
& $<1.29 \mathrm{mmol} / 1(<50 \mathrm{mg} / \mathrm{dl})$ in women \\
\hline Abnormal blood pressure & $\geq 130 / \geq 85 \mathrm{mmHg}$ \\
\hline Abnormal fasting blood glucose & $\geq 6.1 \mathrm{mmol} / 1(\geq 110 \mathrm{mg} / \mathrm{dl})$ \\
\hline
\end{tabular}

collected. Subsequently, fasting venous blood sampling took place, followed by an oral glucose tolerance test with 75 g glucose. We measured plasma insulin levels at 0 and 120 minutes (method: enzyme-immunoassay, Abbott kit), and using routine laboratory methods, from the fasting blood sample lipids, fibrinogen, CRP (high sensitivity C-reactive protein) and adiponectin values were determined (ELISA method, AviBion kit) .

The current status of glucose metabolism was determined from the 0 and 120 minute blood glucose values, based on the WHO criteria (9) (Tab. 1). The following categories were distinguished: normal glucose metabolism, pre-diabetes (IFG: impaired fasting glucose, IGT: impaired glucose tolerance) and type 2 diabetes mellitus. HOMA-IR value reflecting insulin resistance was calculated by the following formula used in the literature (10): HOMA-IR = fasting blood glucose $(\mathrm{mmol} / \mathrm{l}) \mathrm{x}$ fasting insulin $(\mu \mathrm{U} / \mathrm{ml}) / 22.2$. The diagnosis of metabolic syndrome was based on the ATP-III criteria (11) (Tab. 2). If a subject received antihypertensive therapy, he/she was considered as having abnormal blood pressure regardless of the actual blood pressure value.

The study was approved by the Ethics Committee of the Petz County Teaching Hospital, Györ. Participation in the screening was voluntary; all subjects provided written informed consent prior to participation. The subject and the general practitioner were informed about the results of the screening in each case, and if needed, treatment was recommended.

The study population was characterized by descriptive statistics; Student's 2-sample t-test was used for inter-group comparisons. Besides the average, standard deviation $(\mathrm{x} \pm \mathrm{SD})$ values were given. A value of $p<0.05$ was considered statistically significant.

\section{Results}

From the individual components of the metabolic syndrome abnormal blood pressure was observed most frequently, followed by abnormal waist circumference, abnormal HDL-cholesterol, abnormal serum triglycerides and finally abnormal fasting blood glucose (Tab. 3).

Within the cohort, metabolic syndrome could be diagnosed in 39 individuals $(50.6 \%)$ without a significant gender difference (males 20/35 = 57.1\%; women: 19/42=45.2\%, p>0.05) (Tab. 4).

Among the 77 individuals screened diabetes mellitus was detected in 14 cases $(18.2 \%$ ), and pre-diabetes (IFG, IGT) could be diagnosed in a further 14 cases $(18.2 \%)$.

A number of data not included in the diagnostic criteria differed significantly between the subjects with metabolic syndrome $(\mathrm{n}=39)$ and the unaffected individuals $(\mathrm{n}=38)$. Patients with metabolic syndrome were older, had higher BMI, post-load blood glucose, fasting and post-load plasma insulin levels, HOMA-index

Tab. 3. The frequency of abnormal clinical/laboratory data within the screened Gypsy population $(n=77)$.

\begin{tabular}{|c|c|c|c|}
\hline & $\operatorname{Men}(n=35)$ & Women $(n=42)$ & Total $(n=77)$ \\
\hline Abnormal waist circumference & $17(48.6 \%)$ & $23(54.8 \%)$ & $40(51.9 \%)$ \\
\hline Abnormal serum triglycerides & $18(51.4 \%)$ & $17(40.5 \%)$ & $35(45.5 \%)$ \\
\hline Abnormal serum HDL-cholesterol & $16(45.7 \%)$ & $23(54.8 \%)$ & $39(50.6 \%)$ \\
\hline Abnormal blood pressure & $23(65.7 \%)$ & $24(57.1 \%)$ & $47(61.0 \%)$ \\
\hline Abnormal fasting blood glucose & $9(25.7 \%)$ & $6(14.3 \%)$ & $15(19.5 \%)$ \\
\hline
\end{tabular}


Tab. 4. The frequency of the individual components of the metabolic syndrome within the screened Gypsy population $(n=77)$. The prevalence of metabolic syndrome (number of abnormal parameters $\geq 3$ ) was $50.6 \%$ (men $57.1 \%$, women: $45.2 \%$ ).

\begin{tabular}{lrrr}
\hline $\begin{array}{l}\text { Number of } \\
\text { abnormal } \\
\text { parameters }\end{array}$ & Men $(\mathrm{n}=35)$ & Women $(\mathrm{n}=42)$ & Total $(\mathrm{n}=77)$ \\
\hline 0 & $5(14.3 \%)$ & $7(16.7 \%)$ & $12(15.6 \%)$ \\
$\geq 1$ & $30(85.7 \%)$ & $35(83.3 \%)$ & $65(84.4 \%)$ \\
$\geq 2$ & $23(65.7 \%)$ & $28(66.7 \%)$ & $51(66.2 \%)$ \\
$\geq 3$ & $20(57.1 \%)$ & $19(45.2 \%)$ & $39(50.6 \%)$ \\
$\geq 4$ & $9(25.7 \%)$ & $10(23.8 \%)$ & $19(24.7 \%)$ \\
5 & $1(2.9 \%)$ & $1(2.4 \%)$ & $2(2.6 \%)$ \\
\hline
\end{tabular}

value and lower serum adiponectin than the individuals without metabolic syndrome. The two groups did not differ significantly in serum total cholesterol, CRP and fibrinogen values (Tab. 5).

\section{Discussion}

The results of the study draw attention to the fact that among the Gypsy population the metabolic syndrome, pre-diabetes and type 2 diabetes occur frequently.

Although the study cannot be considered representative, we think our data is remarkable. The prevalence of metabolic syndrome (according to the ATP III criteria) was much higher (50.6\%, men $57.1 \%$; women $45.2 \%$ ) in our study cohort than in the representative Hungarian population $(25.0 \%$, men $26,0 \%$, women $24.1 \%$ ) (12), or that of adults in the care of general practitioners $(8.3 \%$, men $6.7 \%$, women $9.8 \%$ ) (13). The prevalence rate approached that of high risk individuals (obese and/or hypertensive adults, $66.2 \%$, men $70.3 \%$, women $68.5 \%$ ) (14). The frequency of type 2 diabetes (18.4\%) also proved to be higher than that of the representative population in Hungary $(7.47 \%)(15)$. The occurrence of type 2 diabetes and prediabetes together $(36.4 \%$ ) was found to be higher than that of high risk individuals (obese and/or hypertensive adults, $23.1 \%$ ) (14).

Previous investigations conducted among the Gypsy population in Hungary studied the causes of child mortality, the shorter life expectancy and documented the higher incidence of infectious diseases and higher number of suicide attempts $(16,17,18)$. Recently published data report worse outcome indicators of kidney transplanted Gypsy patients (19). Using questionnaires and a comparative method Kósa et al. have published data regarding the prevalence of cardiovascular risk factors (obesity, smoking) (20). In the national literature we have not found any reports about data collection using a screening method among the Gypsy population similar to ours.

Data regarding the health care status of Gypsy people living in neighboring countries can be found in the international literature. The data published from Slovakia are remarkable (21). According to a survey conducted among the Gypsy population published a few years ago, the occurrence of type 2 diabetes, metabolic syndrome and cardiovascular diseases has proved to be significantly higher than in the non-Gypsy population (22). Gypsy individuals living in Slovakia had higher fasting insulin levels (23) and among Gypsy women obesity was more common compared to non-Gypsy subjects (24). Cardiovascular risk factors appeared in the younger
Tab. 5. Main clinical/laboratory data of the Gypsy subjects with metabolic syndrome $(n=39)$ and the unaffected individuals $(n=38)(x \pm S D)$.

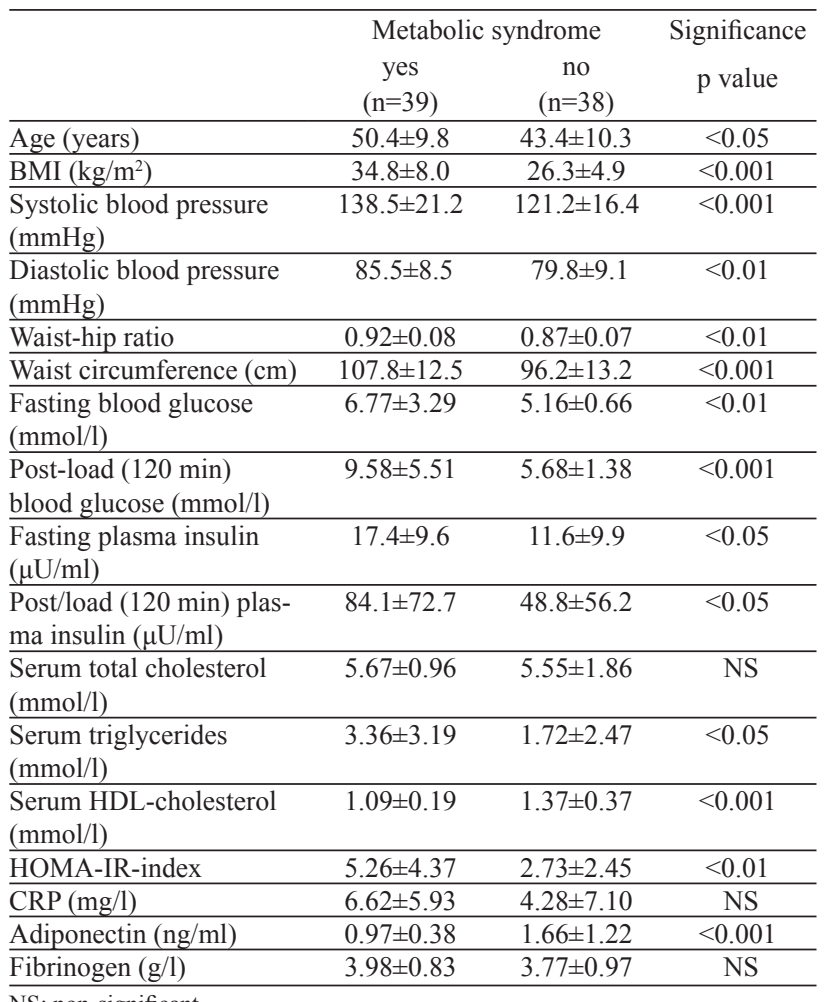

NS: non-significant

age group more frequently in the Slovakian Gypsy individuals compared to the non-Gypsy population (25). An anthropological and epidemiological study conducted among Gypsy subjects living in the northern part of Croatia near the border with Hungary has demonstrated that traditional cardiovascular risk factors (hypertension, smoking, obesity) are common also among this ethnic minority $(26,27)$. An analysis of mortality within the Gypsy population from Serbia (28) pointed out that the leading cause of death were cardiovascular diseases according to the death statistics for 2002 and 2005 (44.5\% and $46.1 \%$, respectively).

Our screening could not provide data regarding the causes of the frequent occurrence of metabolic syndrome. From other studies we know that obesity, metabolic syndrome and type 2 diabetes mellitus occur more often among subjects living under poorer social circumstances and with lower educational attainment $(29,30)$. Several surveys have shown that the average social conditions of the Gypsy people in Hungary fall far short of the average, and it is typical that some children do not complete even the eight years of primary school. The majority of Gypsy live in closed communities, where food and lifestyle habits are similar. It has been noted that endogamy is not uncommon among the Gypsy population, which could lead to the conservation and homozygosity of the gene pool (31). Several earlier surveys showed that the use of the health care system and participation rate in any screening is lower within the Gypsy people compared to the general population $(2,32)$.

A limitation of our study is that the number of subjects included in the screening is lower than planned. One of the reasons for this 
is that the importance of the screening was difficult to communicate to the target population, even though we had preferentially worked with Gypsy health workers and engaged their interest in persuading target families. Secondly, there was a significant difference in the number of subjects participating in the screening and actually being involved in the study as - according to the preliminary consultation with the Ombudsman for Minorities - at the signing of the informed consent only those could be considered Gypsy who declared themselves to belong to this ethnic minority. Clearly at present this is the only correct and recommended procedure to identify ethnicity, but because of this principle not only us but also others $(2,32)$ had a lot of practical problems. The fear of stigmatization may explain - in a broader sense - that the number of people declaring themselves as Gypsy during a census is far behind the estimated numbers based on other surveys in the country. This also contributes to the fact that we do not have exact figures regarding the size of the Gypsy population in Hungary.

In summary, our data have shown that cardio-metabolic risk factors often occur within the Gypsy population and it can be supposed that this condition is characteristic to a broader range of the Gypsy people. In order to recognise cardio-metabolic risks and to prevent their cardiovascular consequences, continuous health promotion and adequate medical care should be provided for the Gypsy population in Hungary.

\section{References}

1. Hajioff S, McKee M. The health of the Roma people: a review of the published literature. J Epidemiol Community Health 2000; 54: 864-869.

2. Kósa K, Lénárt B, Ádány R. Health status of the Roma population in Hungary (Hungarian). Orv Hetil 2002; 143: 2419-2426.

3. Nádas J, Jermendy Gy. From the metabolic syndrome to the concept of the global cardiometabolic risk (Hungarian). Orv Hetil 2009; 150: 821-829.

4. Després JP, Cartier A, Côté M, Arsenault BJ. The concept of cardiometabolic risk: Bridging the fields of diabetology and cardiology. Ann Med 2008; 40: 514-523.

5. Araneta MRG, Wingard DL, Barrett-Connor E. Type 2 diabetes and metabolic syndrome in Filipina-American women. Diabetes Care 2002; 25: 494-499.

6. Flegal KM, Ezzati TM, Harris MI, et al. Prevalence of diabetes in Mexican Americans, Cubans, and Puerto Ricans from the Hispanic Health and Nutrition Examination Survey, 1982-1984. Diabetes Care 1991; 14: 628-638.

7. Valway S, Freeman W, Kaufman S, Welty T, Helgerson SD, Gohdes D. Prevalence of diagnosed diabetes among American Indians and Alaska Natives, 1987. Diabetes Care 1993; 16: 271-276.

8. O'Dea. Marked improvement in carbohydrate and lipid metabolism in diabetic Australian Aborigines after temporary reversion to traditional life-style. Diabetes 1984; 33: 595-603.

9. World Health Organization: Definition and diagnosis of diabetes mellitus and intermediate hyperglycemia. Report of a WHO consultation. Geneva, 2006.

10. Matthews DR, Hosker JP, Rudenski AS, Naylor BA, Treacher DF, Turner RC. Homeostasis model assessment: insulin resistance and $\beta$-cell function from fasting plasma glucose and insulin concentration in man. Diabetologia 1985; 28: 412-419.

11. Expert panel on detection, evaluation, and treatment of high blood cholesterol in adults: Executive summary of the third report of the National Cholesterol Education Program (NCEP) expert anel on detection, evaluation, and treatment of high blood cholesterol in adults (Adult Treatment Panel III). JAMA 2001; 285: 2486-2497.
12. Szigethy E, Vokó Z, Jermendy G, et al. The epidemiology of metabolic syndrome in the Hungarian adult population (abstract). Diab Vasc Dis Res 2007; 4 Suppl 1: S94.

13. Császár A, Kékes E, Abel T, Papp R, Kiss I, Balogh S. Prevalence of metabolic syndrome estimated by International Diabetes Federation criteria in a Hungarian population. Blood Press 2006; 15: 101-106.

14. Jermendy G, Hetyési K, Bíró L, Hidvégi T. Prevalence of the metabolic syndrome in hypertensive and/or obese subjects. Diabet Med 2004; 21: 805-806.

15. Jermendy G, Nádas J, Szigethy E, et al. Prevalence rate of diabetes mellitus and impaired fasting glycemia in Hungary: cross-sectional study on nationally representative sample of people aged 20-69 years. Croat Med J 2010; 51: 151-156.

16. Joubert K. Size at birth and some sociodemographic factors in gypsies in Hungary. J Biosoc Sci 1991; 23: 39-47.

17. Ungváry G, Odor A, Bényi M, Balogh S, Szakmáry E. Gypsy colonies in Hungary - medical care of children and hygienic conditions (Hungarian). Orv Hetil 2005; 146: 691-699.

18. Zonda T, Lester D. Suicide among Hungarian Gypsies. Acta Psychiatr Scand 1990; 82: 381-382.

19. Langer RM, Hídvégi M, Járay J. Significant differences in the efficacy of kidney transplantation between Hungarian Caucasians and Gipsies. Transplant Proc 2005; 37: 729-730.

20. Kósa Zs, Széles Gy, Kardos L, et al. A comparative health survey of the inhabitants of Gypsy settlements in Hungary. Am J Public Health 2007; 97: 853-859.

21. Ginter E, Krajcovicova-Kudlackova M, Kacala O, Kovacic V, Valachovicova M. Health status of Romanies (Gypsies) in the Slovak Republic and in the neighbouring countries. Bratisl Lek Listy 2001; 102: 479-484.

22. Vozarova de Courten B, Courten M de, Hanson RL, et al. Higher prevalence of type 2 diabetes, metabolic syndrome and cardiovascular diseases in Gypsies than in non-gypsies in Slovakia. Diab Res Clin Pract 2003; 62: 95-103.

23. Krajcovicova-Kudlackova M, Blazicek $P$, Ginter E, Spustova V. Insulin levels in Gipsy minority. Bratisl Lek Listy 2002; 102: 459-461.

24. Dolinsky S, Kudlackova M, Ginter E. The prevalence of female obesity in the world and in the Slovak Gypsy women. Bratisl Lek Listy 2007; 108: 207-211.

25. Krajcovicova-Kudlackova M, Blazicek P, Spustova V, Valachovicova M, Ginter E. Cardiovascular risk factors in young Roma population. Bratisl Lek Listy 2004; 105: 256-259.

26. Zeljko H, Skaric-Juric T, Narancic NS, et al. Traditional CVD risk factors and socio-economic deprivation in Gypsy minority population of Croatia. Coll Antropol 2008; 32: 667-676.

27. Skaric-Juric T, Klaric IM, Narancic NS, et al. Trapped between tradition and transition - anthropological and epidemiological cross-sectional study of Bayash Roma in Croatia. Croat Med J 2007; 48: 708-719.

28. Bogdanovic D, Nikic D, Petrovic B, et al. Mortality of Roma population in Serbia, 2002-2005. Croat Med J 2007; 48: 720-726.

29. Monterio CA, Conde WL, Popkin BM. Obesity and inequities in health in the developing world. Int J Obesity 2004; 28: 1181-1186.

30. Hidvégi T, Hetyési K, Bíró L, Jermendy Gy. Education level and clustering of clinical characteristics of metabolic syndrome. Diabetes Care 2001; 24: 2013-2014.

31. Assal S, Susanszky E, Czeizel A. High consanguinity rate in Hungarian gipsy communities. Acta Paediatr Hung 1991; 31: 299-304.

32. Kósa K, Ádány R. Studying vulnerable populations: lessons from the Gypsy minority. Epidemiology 2007; 18: 290-299.

Received March 14, 2011. Accepted September 20, 2012. 